\title{
Environmental Literacy in Science and Society: From Knowledge to Decisions. By Roland W. Scholz. Cambridge University Press: New York, USA, 2011; Hardback, 631 pp; ISBN 978-0-521-19271-2; Paperback, ISBN 978-0-521-18333-8
}

\section{Ralph Hansmann}

Department of Environmental Systems Science (D-USYS), ETH Zurich, ETH Zurich SOL F.7, Sonneggstrasse 33, CH-8092 Zürich, Switzerland; E-Mail: hansmann@env.ethz.ch;

Tel.: +41-44-632-6316; Fax: +41-44-632-1029

Received: 26 April 2012 / Accepted: 27 April 2012 / Published: 3 May 2012

The book Environmental Literacy in Science and Society contributes to the scientific understanding and sustainability-oriented management of Human-Environment Systems (HES) based on processes of transdisciplinarity and mutual learning. It presents a historical analysis, and modern explanations, of crucial concepts and developments regarding environmental literacy in science and society. In addition, it presents an original framework for the analysis of HES in which these are seen as inextricably coupled transactional systems. This framework is applied in the book to sustainability learning and decision making in real-world problem-solving processes with respect to complex, illdefined problems that pose threads to the balance of certain aspects of HES or to the anthroposphere as a whole. The assumption of a distinctive and complementary relationship between "reality" and its functional (re)construction in human systems based on perceptual, cognitive and communicative epistemic processes referring to Egon Brunswik's lens model and theory of probabilistic functionalism [1], which also entails possibilities for profound misconceptions of reality, is a central cornerstone of the HES framework. Therefore, applying this framework requires the integration of multiple epistemic sources and facets through inter- and transdisciplinary processes of mutual learning between science and society. This is meant to maximise the potential for an appropriate analysis, an adequate conceptualisation and an in depth understanding of sustainability issues. Thus, the potential for generating viable strategies and options, as well as for having functional decision making or transition management, shall be maximised. The manifold forms of synthesis that can contribute to this goal include integrating varying perspectives of scientific disciplines (e.g., the humanities, natural sciences, social sciences), modes of thought (e.g., analytic thinking and intuitive thinking), forms of knowledge (qualitative and quantitative, scientific and experiential), interests (e.g., mediation between stakeholder groups, population), values (monetary, ethics) and both human (e.g., legal, political, economic, educational) and environmental systems (e.g., water, air, soil). Perception, awareness, communication 
and decision-making form part of the regulatory processes in the human-systems component of HES, which are conceptualised hierarchically by distinct overlapping regulatory levels ranging from cells and organs to individuals, groups, organisations, society and supranational systems. By their actions, these are all able to trigger short-term consequences and long-term dynamics in human and environmental systems. The book investigates and explains the different rationales of regulation that are found in hierarchically overlapping coupled human and environmental systems of diverse scales and how these regulatory processes interact in the short and long terms. In order to demonstrate how such interferences and regulation mechanisms function between and within different scales, the book takes into account the full range of environmental scales, looking from the micro-cosmos of genes and the 'environmental literacy' of the immune system to the macro-cosmos of sustainability learning and environmental literacy in the context of supranational systems and world development. The time frame applied to these and to spatially intermediate topics ranges from the beginning of human consideration, through to the first scientific milestones and their proponents, and finishes with contemporary scientific discoveries and discourse. The socio-constructivist consideration of worldviews, belief systems and technological tools - which influence how objective bio-physical entities, processes and relationships have been perceived, interpreted and (re)constructed within human systems-is emphasised in the book. It is done so not only in relation to the thoughts of pioneers but also in relation to current knowledge and scientific inquiry. In the course of the book, historical roots and theory of science perspectives regarding the concepts of environment, environmental literacy and transdisciplinarity are followed by separate sections describing the contributions of psychology, sociology, economics and industrial ecology, leading to the author's framework for investigating HES and environmental literacy.

In keeping with the didactic nature of modern teaching books, advance organisers are provided (e.g., in the form of a roadmap for the book as well as by means of key questions and chapter previews), key messages are formulated at the end of each chapter and many boxes with fascinating examples that illustrate and complement the main text are inserted throughout the book. It is, as such, a valuable, intelligible and well-structured teaching resource for university courses in a broad array of studies, including environmental and sustainability sciences, ecology, planning, engineering, management and environmentally oriented branches of sociology, economics, psychology, behavioural biology and similar fields. However, the scope of this book, and the readership who will be interested in it, goes beyond university teaching. It is recommended for researchers and professionals who are active in the aforementioned fields and, generally speaking, for all those concerned with managing HES and with striving for sustainable paths of action in local or world development. The book is suitable, too, for enhancing the environmental literacy of non-professional readers who are politically and environmentally engaged, intellectually capable and open-minded; who have an interest in sustainability science; and who are interested in the theory, history and philosophy of natural, environmental and behavioural sciences. The book's emphasis on the historical development and theory of science and on the central role of epistemic processes required that philosophical foundations are clarified. The author takes social-constructivist and probabilistic-functionalist stances in this regard, which rely heavily on empirical observation, scientific theory and models but which, at the same time, emphasise that objective reality and its corresponding models need to be considered as separate, though functionally related, entities. Models of reality, therefore, need to be carefully constructed by integrating information and knowledge from diverse sources in order to maximise the 
probability of developing adequate and functional representations. Thus, in my view in particular, the presentation of the HES framework makes this book valuable for all those active in the fields of environmental and sustainability science and practice.

Table of content of the book and other book reviews can be found online at Cambridge University Press [2].

\section{References}

1. Brunswik, E. Representative design and probabilistic theory in a functional psychology. Psychol. Rev. 1955, 62, 193-217.

2. Environmental Literacy in Science and Society. Academic and Professional Books; Cambridge University Press: Cambridge, UK, 2012. Available online: http://www.cambridge.org/gb/ knowledge/isbn/item6047353/?site_locale=en_GB (accessed on 20 April 2012).

(C) 2012 by the author; licensee MDPI, Basel, Switzerland. This article is an open access article distributed under the terms and conditions of the Creative Commons Attribution license (http://creativecommons.org/licenses/by/3.0/). 